\title{
Evaluation of the Microring YT system for identifying clinical yeast isolates
}

\author{
E J Ridgway, K D Allen
}

\begin{abstract}
The Microring YT is a commercial system for identifying clinical yeast isolates. The system uses a series of discs impregnated with inhibitory agents mounted on a ring. The pattern of growth and inhibition produced provides a six digit code which can be compared with a table provided by the manufacturer. The performance of this system was compared with the API $32 \mathrm{C}$ in the identification of 606 yeast isolates (355 clinical and 251 environmental strains). The Microring YT system was in $72.6 \%$ agreement with the API $32 \mathrm{C}$ system. The sensitivity of identification of different species varied from $38 \%$ to $100 \%$.

The API 32C system has a more extensive database than the Microring YT and is thus more reliable for use, but it is considerably more expensive. It is concluded that although the Microring YT is cheap, easy, and convenient to use, it is inadequate for many common Candida species.
\end{abstract}

The prevalence of opportunistic yeast infections is increasing, especially in renal transplant recipients, oncology and other immunocompromised patients. ${ }^{12}$ Many of these infections are fatal so rapid identification of an infecting strain is important, especially as some strains show natural or acquired antifungal resistance-for example, Candida lusitaniae. ${ }^{2}$ Accurate identification permits a better understanding of the clinical importance of various yeast species and allows mycoserological tests to be interpreted. Conventional identification methods are time consuming and complex. Consequently several new methods of yeast identification have become available for clinical use, most offering convenience in addition to rapidity. ${ }^{34}$

The Microring YT is a new commercial system based on a test devised by Sobczak. ${ }^{5}$ It uses the differing susceptibilities of yeast strains to six discs (mounted on a filter paper ring) which are impregnated with chemicals or dyes (Janus green, ethidium bromide, triphenyl tetrazolium chloride, brilliant green, cycloheximide and rhodamine $6 \mathrm{G}$ ) to generate a six digit code. The code is compared with a list of profiles provided by the manufacturer.

We compared the Microring $\mathrm{YT}$ to an established system (API 32C) to determine whether it was a rapid, reliable, and accurate method that could be used easily in a diagnostic microbiology laboratory.

\section{Methods}

A total of 606 yeast strains were examined, representing 13 yeast species. Three hundred and fifty five (13 species) were recent clinical isolates from patients on the intensive care unit and 251 (nine species) were environmental isolates collected from the unit over the same seven month period. Clinical specimens were collected from multiple sites from each patient-for example, throat, rectal, urine, wound, interdigital. Thirty eight $(9 \%)$ clinical isolates were repeat isolates from the same site but after an interval of at least seven days.

All strains were germ tube negative. Germ tube positive isolates were not included as these would normally be identified as Candida albicans and no further identification undertaken. ${ }^{6}$ All isolates were stored on Sabouraud's glucose agar (SGA) slopes (CM 41; Oxoid Ltd, Basingstoke, United Kingdom) at room temperature and tested within six weeks of isolation. All strains were subcultured on to SGA plates to check for purity before testing. Two commercial kits were used to identify the organisms, the API 32C (API-BioMèrieux, Basingstoke, United Kingdom) and the Microring YT (Medical Wire and Equipment Co Ltd, Corsham, United Kingdom).

The API $32 \mathrm{C}$ was performed according to the manufacturer's instructions. Kits were stored at $4^{\circ} \mathrm{C}$ until used. After incubation at $30^{\circ} \mathrm{C}$ for 48 hours the biotype number of the unknown yeast was compared with those in a database compendium supplied by the manufacturer.

With the Microring YT system, the test organism was emulsified in $3 \mathrm{ml}$ sterile distilled water to give a density equivalent to a No 1-No $2 \mathrm{McF}$ arland standard. This was spread across the surface of an SGA plate with a sterile swab. When the surface had dried, a Microring was placed in the centre of the plate with sterile forceps and gently pressed down to ensure good contact with the surface of the agar. After incubation at $37^{\circ} \mathrm{C}$ for 24 to 48 hours the plates were examined for zones of growth inhibition, the colour of the yeast growth, and the presence of regrowth within any inhibition zone around the discs. Each disc on the Microring is numbered 1-6. Inhibition of growth around a disc was scored with the number of that disc; absence of inhibition was scored as 0 . Thus a six digit code was generated-for example, 120406. This code was compared with a list of profile numbers and zone sites provided by the manufacturer. Inhibition zone sizes, presence of regrowth, and coloration of the growth were used to discriminate between species giving the same code. If the code given by the unknown 
Table 1 Comparison of Microring YT and API 32C systems for identification of clinical and environmental isolates

\begin{tabular}{|c|c|c|}
\hline \multirow[b]{3}{*}{$A P I 32 C$} & \multicolumn{2}{|c|}{ Microring $Y T$} \\
\hline & \multicolumn{2}{|c|}{ Clinical and environmental isolates } \\
\hline & Agreement & “Incorrect" identification " \\
\hline Candida albicans & $158 / 166$ & $\begin{array}{l}\text { Candida pseudotropicalis } \\
(5) \\
\text { No identity (2) } \\
\text { Candida parapsilosis }\end{array}$ \\
\hline $\begin{array}{l}\text { Candida krusei } \\
\text { Candida glabrata }\end{array}$ & $\begin{array}{c}4 / 4 \\
58 / 65\end{array}$ & $\begin{array}{l}\text { No identity (5) } \\
\text { Candida krusei (2) }\end{array}$ \\
\hline Candida lusitaniae & $44 / 51$ & $\begin{array}{l}\text { Candida albicans (4) } \\
\text { Candida krusei (3) }\end{array}$ \\
\hline Candida parapsilosis & $100 / 220$ & $\begin{array}{l}\text { Candida lusitaniae (46) } \\
\text { No identity (26) } \\
\text { Candida albicans (14) } \\
\text { Geotrichum sp (14) } \\
\text { Candida krusei }(11) \\
\text { Candida glabrata (4) } \\
\text { Candida tropicalis } \\
\text { Saccharomyces cerevisiae } \\
\text { Candida guilliermondii } \\
\text { Candida famata } \\
\text { Candida pseudotropicalis }\end{array}$ \\
\hline Candida guilliermondii & $9 / 24$ & $\begin{array}{l}\text { Candida famata (9) } \\
\text { Candida lusitaniae (4) } \\
\text { Candida krusei (2) }\end{array}$ \\
\hline $\begin{array}{l}\text { Saccharomyces } \\
\text { cerevisiae }\end{array}$ & $3 / 7$ & $\begin{array}{l}\text { No identity (2) } \\
\text { Candida glabrata (2) }\end{array}$ \\
\hline Candida tropicalis & $53 / 55$ & $\begin{array}{l}\text { Candida albicans } \\
\text { Candida pseudotropicalis }\end{array}$ \\
\hline Candida famata & $2 / 2$ & \\
\hline
\end{tabular}

^For the purpose of comparison, API 32C was assumed to b "correct".

yeast was not in the list of profile numbers or if the zone sizes, regrowth, or coloration were discrepant, the isolate was recorded as "no identity". Isolates were processed blind and at random and all plates were read by the same operator.

In this study it was assumed that the identities given by the API 32C were correct, and the performance of the Microring YT was assessed against this standard.

The sensitivity and specificity of detection and the predictive value of a positive and a negative test were determined for each species identified by the Microring YT. ${ }^{\text {? }}$

\section{Results}

With the API system, 13 different species were identified among the patient isolates and nine of these were found in the enrivonment (table 1). Only one species (Candida famata) was found exclusively in the environment so patient and environmental isolates were combined. One hundred and sixty six of the 606 germ tube negative isolates under investigation were $C$ albicans. This represents $36 \%$ of all $C$ albicans

Table 2 Sensitivity and specificity of species identification with Microring $Y T$, with predictive values of identification

\begin{tabular}{lcccc}
\hline & Sensitivity & $\begin{array}{l}\text { Specificity } \\
\%\end{array}$ & $\begin{array}{l}\text { Positive } \\
\text { predictive } \\
\text { value } \\
\%\end{array}$ & $\begin{array}{l}\text { Negative } \\
\text { predictive } \\
\text { value } \\
\%\end{array}$ \\
\hline Candida albicans & 95 & 98 & 95 & 98 \\
Candida krusei & 100 & 97 & 22 & 100 \\
Candida glabrata & 89 & 99 & 91 & 99 \\
Candida lusitaniae & 86 & 91 & 47 & 99 \\
Candida parapsilosis & 45 & 100 & 100 & 76 \\
Saccharomyces cerevisiae & 43 & 100 & 75 & 99 \\
Candida tropicalis & 100 & 100 & 98 & 100 \\
Candida famata & 100 & 98 & 20 & 100 \\
Candida guilliermondii & 38 & 100 & 90 & 97 \\
\hline
\end{tabular}

Table 3 Identification of species not included in Microring $Y T$ database

\begin{tabular}{lll}
\hline & \multicolumn{2}{l}{ Microring $Y T$} \\
\cline { 2 - 3 } API 32C & \multicolumn{2}{c}{ Clinical and environmental isolates } \\
\cline { 2 - 3 } Agreement & "Incorrect" identification \\
\hline Candida melibiosica & $0 / 2$ & Candida lusitaniae (2) \\
Trichosporon capitatum & $0 / 2$ & $\begin{array}{l}\text { Candida krusei (4) } \\
\text { No identity (2) }\end{array}$ \\
Trichosporon cutaneum & $0 / 2$ & $\begin{array}{l}\text { Candida pseudotropicalis } \\
\text { Candida krusei }\end{array}$ \\
\hline
\end{tabular}

$\star$ For the purpose of comparison, API $32 \mathrm{C}$ was assumed to be "correct".

isolates from the study period. This proportion of germ tube negative strains is higher than might be expected, as $95-97 \%$ of clinical isolates of $C$ albicans are germ tube positive in serum. ${ }^{6}$ This finding may result from the inclusion of more than one clinical isolate of $C$ albicans from each patient (mean 2.6, range 1-11), especially if patients were extensively colonised with atypical strains.

Nine of the 13 species identified by API 32C were included in the Microring YT database (594 of 606 isolates $(98 \%)$ ).

Four hundred and thirty one of the 594 isolates that were in the Microring YT database were correctly identified $(72 \cdot 6 \%$ ) (table 1 ). Thirty five $(5.9 \%)$ strains could not be identified. Agreement between the API and Microring systems varied between 38 and $100 \%$ for different species; it was less than $50 \%$ for three species (Candida parapsilosis, Saccharomyces cerevisiae, and $C$ guilliermondii) (table 1). Notably, Candida parapsilosis gave a wide range of misidentifications but was frequently identified as Candida lusitaniae $(20.9 \%)$. The predictive value of identification of some species was very poor (table 2), with three species (Candida krusei, $C$ lusitaniae, and $C$ famata) having values of less than $50 \%$.

Twelve isolates belonged to species not included in the Microring YT database. Only four of these gave "no identity", eight giving "false" identification (table 3).

\section{Discussion}

There has been one previously published evaluation of the Microring YT, where 142 isolates were examined in three laboratories. Only $52.8 \%$ of isolates were correctly identified in all laboratories. Our finding that $72.6 \%$ of strains were correctly identified may reflect the large numbers of commonly isolated species included in our group of isolates. We found that accurate identification of many species was a problem with the Microring YT. The method sheet supplied with the rings states that any zones, however small, should be scored as susceptible. Although a single observer read all the plates, considerable difficulty was often found in deciding whether there was total inhibition of growth around a disc. Even with experience, interpretation was sometimes very subjective. This would obviously impair reproducibility in most laboratories, where it is unlikely that the same person would read all 
tests. Lack of reproducibility may have contributed to the lower identification rate found in the previous study. ${ }^{8}$

The Microring YT has a limited database of only 18 species. This is smaller than other yeast identification systems ${ }^{34}$ and may be difficult to enlarge with only six tests on each ring and a limited number of discriminatory factors. The sensitivity of detection of several common species was found to be very poor with a positive predictive value of below $50 \%$.

Compared with the API 32C, the Microring $\mathrm{YT}$ is very quick and simple to use, requires no special equipment, needs very little storage space and is considerably cheaper (about $£ 0.40 /$ test compared with $£ 2.00 /$ test). This is at the expense of being difficult to read, however, having a limited database and poor sensitivity for several species.

In a routine diagnostic microbiology laboratory most yeast isolates do not require full identification. In the few cases where it is important to identify accurately clinically important isolates, we feel that the performance of the Microring YT is inadequate, its advantages are outweighed by its disadvantages, and another identification method should be used.

1 Merz WG, Karp JE, Schron D, Saral R. Increased incidence of fungaemia caused by Candida krusei. J Clin Microbiol of fungaemia cause

2 Blinkhorn RJ, Adelstein D, Spagnuolo PJ. Emergence of a new opportunistic pathogen, Candida lusitaniae. J Clin Microbiol 1989;27:236-40.

3 Land G, Stotler R, Land K, Staneck J. Update and evaluation of the AutoMicrobic yeast identification system. J Clin Microbiol 1984;20;649-52.

4 El-Zaatari M, Pasarell L, McGinnis MR, Buckner J, Land GA, Salkin IF. Evaluation of the updated Vitek yeast identification data base. J Clin Microbiol 1990;28:1938-41.

5 Sobczak H. A simple disk-diffusion test for differentiation of yeast species. J Med Microbiol 1985;20:307-16.

6 Buckley HR. Identification of yeasts. In: Evans EGV, Richardson MD, eds. Medical mycology, a practical approach. Oxford: IRL Press at Oxford University Press, 1989:97-109.

7 Galen RS, Gambino SR. Beyond normality: the predictive value and efficiency of medical diagnosis. New York: John value and efficiency of

8 Shankland GS, Hopwood V, Forster RA, Evans EGV, Richardson MD, Warnock DW. Multicentre evaluation of Microring YT, a new method of yeast identification. J Clin Microbiol 1990;28:2808-10. 